\title{
Review of Hydrogen Embrittlement in Metals: Hydrogen Diffusion, Hydrogen Characterization, Hydrogen Embrittlement Mechanism and Prevention
}

\author{
Xinfeng $\mathrm{Li}^{1,2} \cdot$ Xianfeng Ma ${ }^{1} \cdot$ Jin Zhang $^{3} \cdot$ Eiji Akiyama $^{4} \cdot$ Yanfei Wang ${ }^{5} \cdot$ Xiaolong Song $^{2}$ \\ Received: 8 October 2019 / Revised: 1 February 2020 / Published online: 22 April 2020 \\ (c) The Chinese Society for Metals (CSM) and Springer-Verlag GmbH Germany, part of Springer Nature 2020
}

\begin{abstract}
Hydrogen dissolved in metals as a result of internal and external hydrogen can affect the mechanical properties of the metals, principally through the interactions between hydrogen and material defects. Multiple phenomena such as hydrogen dissolution, hydrogen diffusion, hydrogen redistribution and hydrogen interactions with vacancies, dislocations, grain boundaries and other phase interfaces are involved in this process. Consequently, several hydrogen embrittlement (HE) mechanisms have been successively proposed to explain the HE phenomena, with the hydrogen-enhanced decohesion mechanism, hydrogenenhanced localized plasticity mechanism and hydrogen-enhanced strain-induced vacancies being some of the most important. Additionally, to reduce the risk of HE for engineering structural materials in service, surface treatments and microstructural optimization of the alloys have been suggested. In this review, we report on the progress of the studies on HE in metals, with a particular focus on steels. It focuses on four aspects: (1) hydrogen diffusion behavior; (2) hydrogen characterization methods; (3) HE mechanisms; and (4) the prevention of HE. The strengths and weaknesses of the current HE mechanisms and HE prevention methods are discussed, and specific research directions for further investigation of fundamental HE mechanisms and methods for preventing HE failure are identified.
\end{abstract}

Keywords Hydrogen embrittlement $\cdot$ Hydrogen diffusion · Hydrogen embrittlement mechanism $\cdot$ Hydrogen embrittlement prevention

\section{Introduction}

Available online at http://link.springer.com/journal/40195.

Xinfeng Li

lixinfeng@mail.sysu.edu.cn

Yanfei Wang

wyf709903@163.com

1 Sino-French Institute of Nuclear Engineering and Technology, Sun Yat-sen University, Zhuhai 519082, China

2 State Key Laboratory for Mechanical Behavior of Materials, Xi' an Jiaotong University, Xi' an 710049, China

3 Department of Physics and Astronomy, Washington State University, Pullman, WA 99164, USA

4 Materials Design Division, Institute for Materials Research, Tohoku University, Sendai 980-8577, Japan

5 School of Chemical Engineering and Technology, China University of Mining and Technology, Xuzhou 221116, China

The degradation of mechanical properties, especially in plasticity, of materials is known as hydrogen embrittlement (HE). $\mathrm{HE}$ is relevant for many metallic materials, including lowalloy steels, precipitation hardening steels, superalloys and aluminum alloys. HE failure always occurs at low stress level with brittle fracture, often causing huge economic losses and even catastrophe. For example, high-strength PSB1080 steels used in wind foundation fractured prematurely owing to HE [1], resulting in an economic loss of five million Yuan and downtime for maintenance. The drawback has driven significant research effort among the industry and academia for the investigation of HE using multi-scale experimental and theoretical methods. It has been generally concluded that hydrogen can decrease the macroscopic and microscopic tensile strength [2-8], fatigue strength [9-11] and fracture toughness [12-16], whereas its effect on fatigue crack propagation rate of steels is still disputed, depending on the frequency or stress ratio level [17]. In addition, cohesive zone modeling related to hydrogen 
proposed by Serebrinsky et al. [18] has been used to evaluate hydrogen-assisted crack initiation and propagation under static and cyclic loading, and obtained numerical simulation results are comparable to the experimental results determined by Wang et al. [19], Olden et al. [20], Xing et al. [21] and Yu et al. [22]. At the nanoscale, dislocations play an important role in hydrogen-induced intergranular crack initiation and propagation [23]. Hydrogen segregation suppresses dislocation emission at the crack tip with a ductile-to-brittle transition, whose process is connected to material states and loading conditions through a kinetic model of hydrogen delivery to the crack tip region [24]. Molecular dynamics simulation results [25-27] imply that hydrogen either has no effect on or promotes or suppresses dislocation motion. However, according to in situ TEM observation results dislocations are dragged by hydrogen [28]. Despite a number of previous studies on the HE of metals, many issues are yet to be clarified such as hydrogen characterization, HE failure criteria and fundamental HE mechanisms. In this review, we discuss four aspects of the HE behavior of metals, particularly steels, namely (1) hydrogen diffusion behavior; (2) hydrogen characterization methods; (3) HE mechanism; and (4) HE prevention.

\section{Hydrogen Diffusion Behavior}

Due to the small radius of hydrogen atoms, hydrogen enters into steels in the form of atoms. High-pressure hydrogen gas, electrochemical hydrogen charging and corrosion reactions are the typical sources of hydrogen in metals.

For high-pressure hydrogen gas, the dissolution of hydrogen involves three steps [29]: The first step is physical absorption on a solid surface due to the van der Waals interactions between the hydrogen gas and the surface, with a low absorption energy of $3-5 \mathrm{~kJ} \mathrm{~mol}^{-1}$. Physical absorption is reversible and it is easy to reach equilibrium. The second step is chemical absorption. Owing to short-range chemical interactions, chemical absorption occurs within single atom layer. In addition, chemical absorption is irreversible and relatively slow because of high hydrogen gas molecule dissociation energy of $4.47 \mathrm{eV}$ and high absorption energy of $40-160 \mathrm{~kJ} \mathrm{~mol}^{-1}$. The third step is hydrogen dissolution. Following chemical absorption, hydrogen atoms diffuse toward the interior of materials owing to the effect of the hydrogen concentration gradient. For highpressure hydrogen gas, the dissolved hydrogen concentration $\left(C_{\mathrm{H}}\right)$ in a metal follows Sieverts' law as [30]:

$C_{\mathrm{H}}=S \sqrt{P_{\mathrm{H}_{2}}}$

where $S$ is the solubility constant that depends on the type of alloys and temperature [31] and $P_{\mathrm{H}_{2}}$ is the hydrogen partial pressure.

For electrochemical hydrogen charging or corrosion reactions, the hydrogen evolution reactions are given by [32]:
$\mathrm{H}_{3} \mathrm{O}^{+}+\mathrm{M} \rightarrow \mathrm{MH}_{\text {ads }}+\mathrm{H}_{2} \mathrm{O}$ Volmer reaction (acid solution)

$\mathrm{H}_{2} \mathrm{O}+\mathrm{M}+\mathrm{e} \rightarrow \mathrm{MH}_{\text {ads }}+\mathrm{OH}^{-}$

Volmer reaction (neutral or alkaline solution)

$\mathrm{MH}_{\mathrm{ads}}+\mathrm{H}_{3} \mathrm{O}^{+}+\mathrm{e} \rightarrow \mathrm{M}+\mathrm{H}_{2}+\mathrm{H}_{2} \mathrm{O}$ Heyrovsky (acid solution)

$\mathrm{MH}_{\text {ads }}+\mathrm{H}_{2} \mathrm{O}+\mathrm{e} \rightarrow \mathrm{M}+\mathrm{H}_{2}+\mathrm{OH}^{-}$

Heyrovsky (neutral or alkaline solution)

$2 \mathrm{MH}_{\mathrm{ads}} \rightarrow 2 \mathrm{M}+\mathrm{H}_{2} \quad$ Tafel reaction

$\mathrm{MH}_{\mathrm{ads}} \rightarrow \mathrm{MH}_{\mathrm{abs}}$

where $\mathrm{M}$ is the metal surface. $\mathrm{MH}_{\mathrm{ads}}$ is the hydrogen absorbed on the metal surface. $\mathrm{MH}_{\mathrm{abs}}$ is the hydrogen dissolved in the materials. Hydrogen atoms attached onto the metal surface are formed through the processes described by Eqs. (2) and (3). Some hydrogen atoms are released in the form of hydrogen molecules, as described by Eqs. (4)-(6). For electrochemical hydrogen charging, the hydrogen content is determined by the hydrogen charging current density, hydrogen charging potential, hydrogen charging time, the type of electrolyte, poisoning agent, hydrogen charging temperature and hydrogen charging method. With increasing $\mathrm{KCN}$ poisoning concentration, the hydrogen fugacity on the pure iron surface increases, and the increase in the overpotential also results in a high hydrogen fugacity under the same electrolyte [33], as shown in Fig. 1a. Compared with gaseous hydrogen charging [34], the equivalent charging pressures caused by electrochemical charging are higher, and their hydrogen concentration is proportional to square root of hydrogen pressure, as shown in Fig. $1 b$.

Some researchers $[31,35,36]$ have found that hydrogen concentration is proportional to the square root of the charging current density, as described by:

$C_{\mathrm{H}}=K \sqrt{i}$

where $K$ is a constant and $i$ is the current density.

Furthermore, hydrogen content in steels is scaled by the electro-migration factor $\varphi$, which can be expressed as [37]:

$\varphi=\frac{Z * e \rho}{k T}$

where $Z *$ is the effective charge number. $e$ is the electron charge. $\rho$ is the resistivity of the alloys. $k$ is the Boltzmann constant. $T$ is the temperature.

For an ideal crystal, hydrogen atoms are preferentially located at BCC tetrahedral or FCC octahedral interstitial sites. At room temperature and 0.1 MPa hydrogen pressure, 

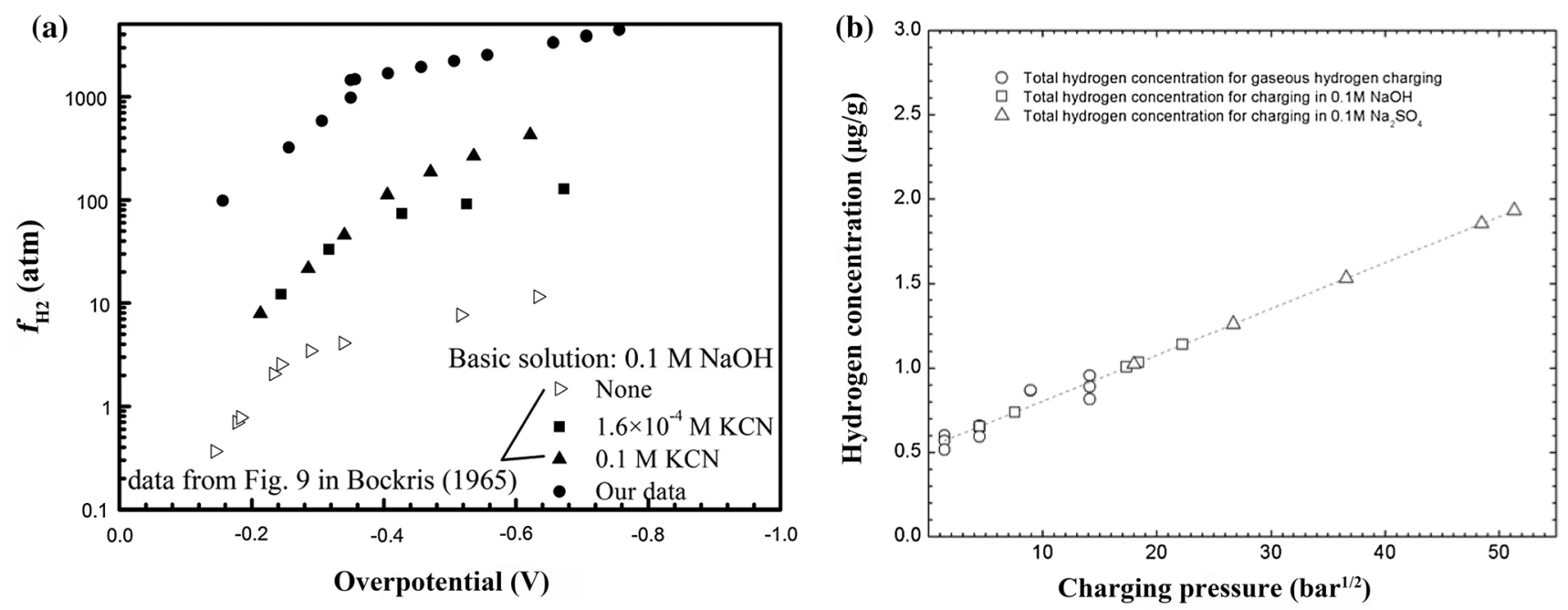

Fig. 1 a Hydrogen fugacity $\left(f_{\mathrm{H} 2}\right)$ for pure iron in $0.1 \mathrm{M} \mathrm{NaOH}$ with different additions of $\mathrm{KCN}$ [33]; b total hydrogen concentration of the 3.5 $\mathrm{NiCrMoV}$ specimens charged electrochemically with hydrogen plotted to fit the regression line for charging in gaseous hydrogen [34]

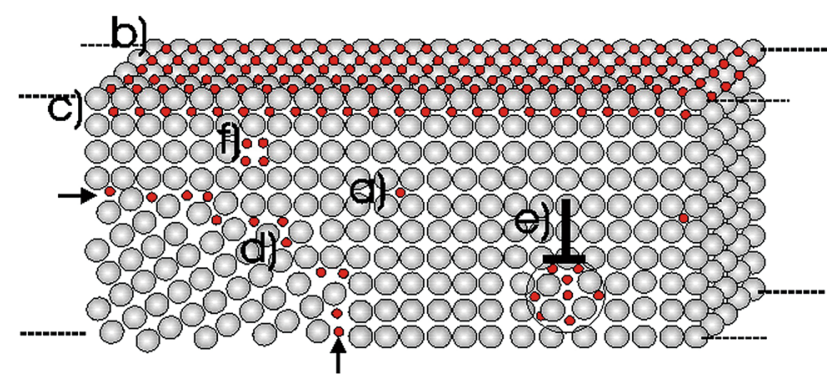

Fig. 2 Hydrogen traps in the steels [39]: a interstitial sites; b surface traps; c subsurface traps; d grain boundary traps; e dislocation traps; f vacancy traps

the atomic ratio of dissolved hydrogen in $\mathrm{BCC}$ iron has a low value of $2 \times 10^{-8}$ according to Sieverts' law [38]. However, in practice, the hydrogen content is always significantly greater than this value owing to the high number of hydrogen traps, such as vacancies, dislocations, grain boundaries and surface hydrogen traps, as schematically shown in Fig. 2.

On the basis of hydrogen trap activation energy $\left(E_{\mathrm{b}}\right)$, these traps are divided into reversible hydrogen traps $\left(E_{\mathrm{b}}<60 \mathrm{~kJ} \mathrm{~mol}^{-1}\right)$ and irreversible hydrogen traps $\left(E_{\mathrm{b}}>60 \mathrm{~kJ} \mathrm{~mol}^{-1}\right)$. Reversible hydrogen traps include interstitial sites, dislocations, lath boundaries, grain boundaries and coherent precipitates, whereas carbides, inclusions and incoherent precipitates are irreversible hydrogen traps. It was reported [40, 41] that the HE susceptibility of alloys is correlated with the presence of reversible hydrogen traps. Table 1 lists the hydrogen traps in steels and their trap activation energies.

Generally, hydrogen atoms are redistributed by stressinduced hydrogen diffusion and dislocation-induced
Table 1 Activation energies of various hydrogen traps in steels [3]

\begin{tabular}{ll}
\hline Trapping sites & $\begin{array}{l}\text { Activation } \\
\text { energy }(\mathrm{kJ} \\
\left.\mathrm{mol}^{-1}\right)\end{array}$ \\
\hline $\begin{array}{l}\text { Reversible trapping sites } \\
\text { Interstitial sites in iron }\end{array}$ & $4-8$ \\
Dislocation & $26.4-26.8$ \\
Lath boundary & $17.8-18.6$ \\
Austenite/martensite & 22 \\
Grain boundary & $17.8-18.6$ \\
$\mathrm{NbC}$ (coherent) & $39-48$ \\
Irreversible trapping sites & \\
Ferrite/cementite interface & $66.3-68.4$ \\
$\mathrm{Fe}_{3} \mathrm{C}$ interface & 84 \\
$\mathrm{Al}_{2} \mathrm{O}_{3}$ interface & 79 \\
$\mathrm{MnS}$ interface & 72 \\
$\mathrm{NbC}^{(i n c o h e r e n t)}$ & $63-68$
\end{tabular}

hydrogen immigration. For stress-induced hydrogen diffusion, the dependence of the local hydrogen concentration $(C)$ on the hydrostatic stress is expressed as:

$C=C_{0} \exp \left(\frac{\sigma_{\mathrm{h}} \overline{V_{\mathrm{H}}}}{R T}\right)$

where $C_{0}$ is the average hydrogen concentration. $\sigma_{\mathrm{h}}$ is the hydrostatic stress. $\overline{V_{\mathrm{H}}}$ is the hydrogen partial molar volume. Additionally, hydrogen can be immigrated through the movement of dislocations as dislocation velocity rate $\left(V^{*}\right)$ during tensile deformation is below the corresponding critical value $\left(V_{\mathrm{C}}\right)$, as described by: 
$V^{*}=\frac{\dot{\varepsilon}}{\rho_{\text {Dis }} b}$

$V_{\mathrm{c}}=\frac{D}{R T} \frac{E_{\mathrm{b}}}{30 b}$

where $\dot{\varepsilon}$ is the tensile strain rate. $\rho_{\text {Dis }}$ is the dislocation density. $b$ is the magnitude of the Burgers vectors. $D$ is the hydrogen diffusion coefficient. $E_{\mathrm{b}}$ is the activation energy of dislocation with hydrogen. In most cases, hydrogen redistribution is achieved through the synergetic effect of stressinduced hydrogen diffusion and dislocation immigration. During hydrogen charging, hydrogen traps near the sample surface are first occupied by hydrogen atoms, following which the hydrogen atoms diffuse toward the interior of the alloys, indicating that hydrogen diffusion parameters are affected by the hydrogen traps. Hence, the relationship between hydrogen trap density $(N)$ and hydrogen diffusion behavior of AISI430 steel was determined as [42]:

$N=\frac{C_{0}}{3}\left(\frac{D_{\mathrm{L}}}{D_{\text {eff }}}-1\right)$

where $C_{0}$ is the hydrogen concentration near the surface. $D_{\mathrm{L}}$ is the lattice hydrogen diffusion coefficient. $D_{\text {eff }}$ is the apparent hydrogen diffusion coefficient. Considering the trap activation energy, the modified relationship is expressed as follows [43]:

$\ln \left(\frac{D_{\mathrm{L}}}{D_{\text {eff }}}-1\right)=\ln \frac{N_{\mathrm{T}}}{N_{\mathrm{L}}}+\frac{E_{\mathrm{b}}}{R} \times \frac{1}{T}$

where $D_{\mathrm{L}}$ is the lattice hydrogen diffusion coefficient. $D_{\text {eff }}$ is the apparent hydrogen diffusion coefficient. $R$ is the gas constant. $T$ is the temperature. Table 2 summarizes the values of the apparent hydrogen diffusion coefficient and apparent hydrogen concentration for different steels.

\section{Hydrogen Characterization Methods}

The content of hydrogen in steels with the BCC structure is extremely low. Usually, HE failure of high-strength steels occurs due to the hydrogen concentration of only several ppm. Moreover, hydrogen atoms are small and can easily move within the metals. Therefore, the accurate measurement of hydrogen content has been intensely investigated, but remains a difficult problem. To date, the prevailing hydrogen characterization methods include the glycerin method (GM), inert gas fusion heat conduction method (IGFHCM), thermal desorption spectroscopy method (TDS), secondary ion mass spectroscopy (SIMS) and atom probe tomography (APT). The former three methods are always used to measure the macroscopic average hydrogen concentration, whereas the local microscopic hydrogen content is determined using the latter two methods. The common principle of GM, IGGHCM and TDS methods is that hydrogen desorption occurs after the samples are heated to some extent. For example, GM was used to measure the average hydrogen concentration of X70 steel [12], and it was found that hydrogen concentration increased with an increase in hydrogen charging current density. Hydrogen behavior in the alloys on the microscale has been characterized by the SIMS technique. It was observed that hydrogen preferentially segregated at the $\mathrm{Al}-(\mathrm{Fe}-\mathrm{Al})$ interfaces [50]. Based on the combination of EBSD and SIMS results, Oudriss et al. [51] concluded that hydrogen diffusion along the general grain boundary was faster than that along the special grain boundary. APT is a powerful tool for the examination of the hydrogen distribution on the nanoscale. Recent research findings demonstrate that hydrogen mainly resides in residual austenite, whereas it is not available at the carbide/ferrite interfaces [52]. Specifically, the hydrogen content in austenite phase (33.9 wppm) is three times higher than that in martensitic phase (10.7 wppm) [53], as shown in Fig. 3a-c. It was also

Table 2 Hydrogen diffusion behavior parameter for some steels

\begin{tabular}{|c|c|c|c|c|}
\hline Type of steels & Grain size $(\mu \mathrm{m})$ & Microstructure & $\begin{array}{l}\text { Apparent hydrogen diffusion } \\
\text { coefficient }\left(\mathrm{m}^{2} \mathrm{~s}^{-1}\right)\end{array}$ & $\begin{array}{l}\text { Apparent hydrogen } \\
\text { concentration (mol } \\
\mathrm{m}^{-3} \text { ) }\end{array}$ \\
\hline Pure iron [44] & - & Ferrite & $5.8 \times 10^{-10}$ & 0.15 \\
\hline 304 steels [45] & - & Austenite & $7.37 \times 10^{-16}$ & 32.51 \\
\hline SAF2205 [20] & - & Ferrite + Austenite & $3.0 \times 10^{-15}$ & - \\
\hline SAE1008 [46] & 19 & Ferritic + carbides & $2.19 \times 10^{-10}$ & 0.49 \\
\hline PSB1080 [47] & 13 & Martensite + bainite & $4.43 \times 10^{-11}$ & 12.21 \\
\hline $300 \mathrm{M}[48]$ & - & Martensite + austenite & $9.6 \times 10^{-12}$ & - \\
\hline PH17-4 [49] & 27 & Martensite $+\mathrm{Cu}$-rich precipitates & $2.18 \times 10^{-12}$ & 1235 \\
\hline PH13-8Mo [49] & 23 & Martensite $+\mathrm{NiAl}$ precipitates & $9.42 \times 10^{-12}$ & 561 \\
\hline
\end{tabular}


found that carbides in the quenching-partitioning-tempering (QPT) steel act as effective non-diffusible hydrogen trapping sites [54], as shown in Fig. 3a-f.

Compared to other hydrogen measurement methods, the TDS method has a unique capability of analyzing the activation energy of hydrogen traps. The activation energy is calculated using the following equation [56]:

$\frac{\partial \ln \left(\frac{\phi}{T_{\mathrm{P}}^{2}}\right)}{\partial \frac{1}{T_{\mathrm{P}}}}=-\frac{E_{\mathrm{a}}}{R}$

where $\phi$ is the heating rate. $T_{\mathrm{P}}$ is the peak temperature. $E_{\mathrm{a}}$ is the hydrogen trap activation energy. $R$ is the gas constant. After obtaining the dependence of $\ln \left(\frac{\phi}{T_{\mathrm{P}}^{2}}\right)$ on $\frac{1}{T_{\mathrm{p}}}$, the trap activation energy of an alloy is estimated from the slope of the fitting curve. Based on the TDS results, the hydrogen trap activation energy at the martensitic lath boundary and the grain boundary is of $18.6 \mathrm{~kJ} \mathrm{~mol}^{-1}$ and $17.8 \mathrm{~kJ} \mathrm{~mol}^{-1}$, respectively, while it is approximately $70.2 \mathrm{~kJ} \mathrm{~mol}^{-1}$ for the matrix/carbide interfaces [57]. The hydrogen micro-print technique (HMT) proposed by Ovejero-Garcia et al. [58] is another key hydrogen characterization method that can be employed to analyze the relationship between the hydrogen distribution and the microscale microstructure. The procedure of the HMT method consists of three steps [58]: (1) The sample surface is coated by an $\mathrm{AgBr}$ emulsion; (2) diffusible hydrogen atoms react with $\mathrm{Ag}^{+}$and generate $\mathrm{Ag}$ particles $\left(\mathrm{Ag}^{+}+\mathrm{H}^{0} \rightarrow \mathrm{Ag}^{0}+\mathrm{H}^{+}\right)$; and (3) the unreacted $\mathrm{AgBr}$ is removed and $\mathrm{Ag}$ particles remain. As the samples are etched, the relationship between hydrogen diffusion pathways and microstructural features of alloys can be elucidated. It was demonstrated that hydrogen evolution in the steels preferentially occurs along the $\delta-\gamma$ interfaces, matrix/inclusion interfaces, grain boundaries and slip lines [58]. According to the HMT results for the IN718 alloy, the hydrogen release rate in the $\gamma$ matrix is higher than that of the $\delta$ phases [59], as

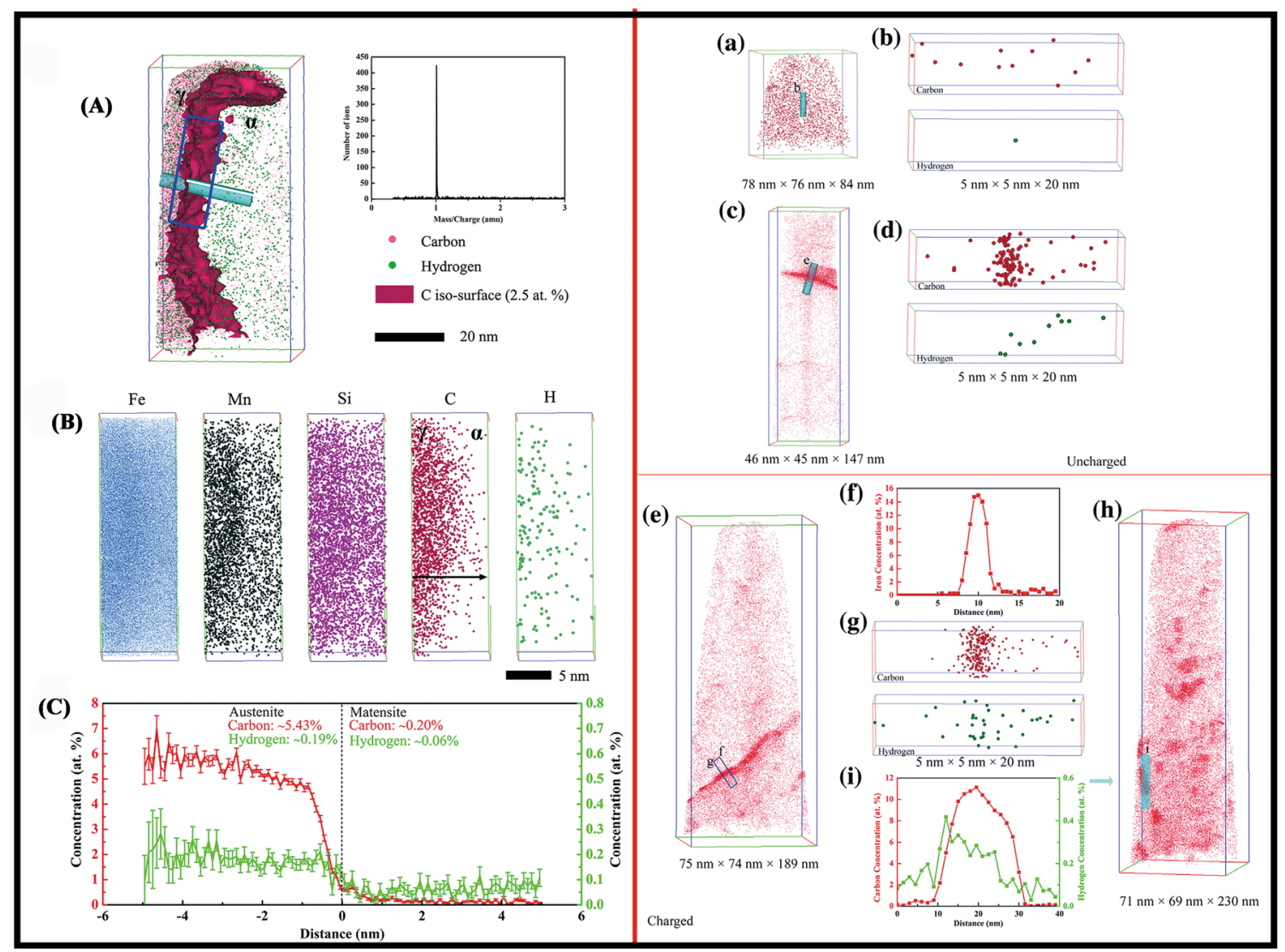

Fig. 3 A-C hydrogen concentration distribution in austenite phase and martensitic phase of QPT steel [55]. A 3DAPT map of a combined atom map of carbon and hydrogen of the as-charged specimen, where iso-concentration surface representing 2.5 at. $\%$ carbon is displayed in red. Carbon atoms and hydrogen atoms are represented by pink and green, respectively. The inserted map is the corresponding mass spectrum. B Atom maps of iron, manganese, silicon, carbon and hydrogen of the selected blue rectangle in $\mathbf{A}$. C Average compositions of carbon and hydrogen along the marked cylinder in A. a-h: Hydrogen concentration distribution in matrix and carbides of QPT steel [6]. b, d, g are enlarged views showing carbon and hydrogen atom distribution as indicated in $\mathbf{a}, \mathbf{c}, \mathbf{e} ; \mathbf{f}$ is the carbon content along the blue cylinder in $\mathbf{e} ; \mathbf{i}$ average compositions of carbon and hydrogen along the blue cylinder in $\mathbf{h}$. Carbon and hydrogen are represented by red and green, respectively 
shown in Fig. 4. The similarities and the differences among the GM, IGFHCM, TDS, SIMS, APT and HMT methods are described in Table 3.

\section{Hydrogen Embrittlement Mechanism}

Hydrogen damage of metals is divided into reversible and irreversible HE. For reversible HE, hydrogen atoms migrate and then accumulate at the potential cracking locations, leading to the delayed fracture of the alloys. By contrast, in irreversible HE, hydrogen atoms combine with each other to form hydrogen molecules at defect sites, generating high hydrogen gas pressure and hydrogen-induced cracking. After a hydrogen removal treatment is conducted, the reversible hydrogen damage of steels is healed, but irreversible HE still remains. So far, many HE mechanisms including the hydrogen pressure theory, hydrogen-induced phase transformation (HIPT) theory, hydrogen-enhanced decohesion mechanism
(HEDE), hydrogen-enhanced localized plasticity mechanism (HELP) and hydrogen-enhanced strain-induced vacancies (HESIV) have been proposed to explain HE phenomena. It is clear that the hydrogen pressure theory and HIPT theory can explain irreversible HE, while reversible HE is mostly rationalized by the HEDE, HELP and HESIV mechanisms. However, it is of consensus that no one HE mechanism is widely accepted for explaining all reversible HE phenomena.

The hydrogen pressure theory first proposed by Zapffe et al. [60] in 1941 states that hydrogen atoms preferentially segregate at defect locations in the metal, such as microvoids and inclusions sites. Then, locally accumulated hydrogen atoms are combined into hydrogen molecules. As time goes on, hydrogen atoms around these defects continuously diffuse toward the defect sites and produce a high hydrogen gas pressure. When the local hydrogen gas pressure exceeds the critical strength of the material, hydrogen-induced cracking takes place. Typically, "fish eye" in the steels and hydrogen-induced cracking of
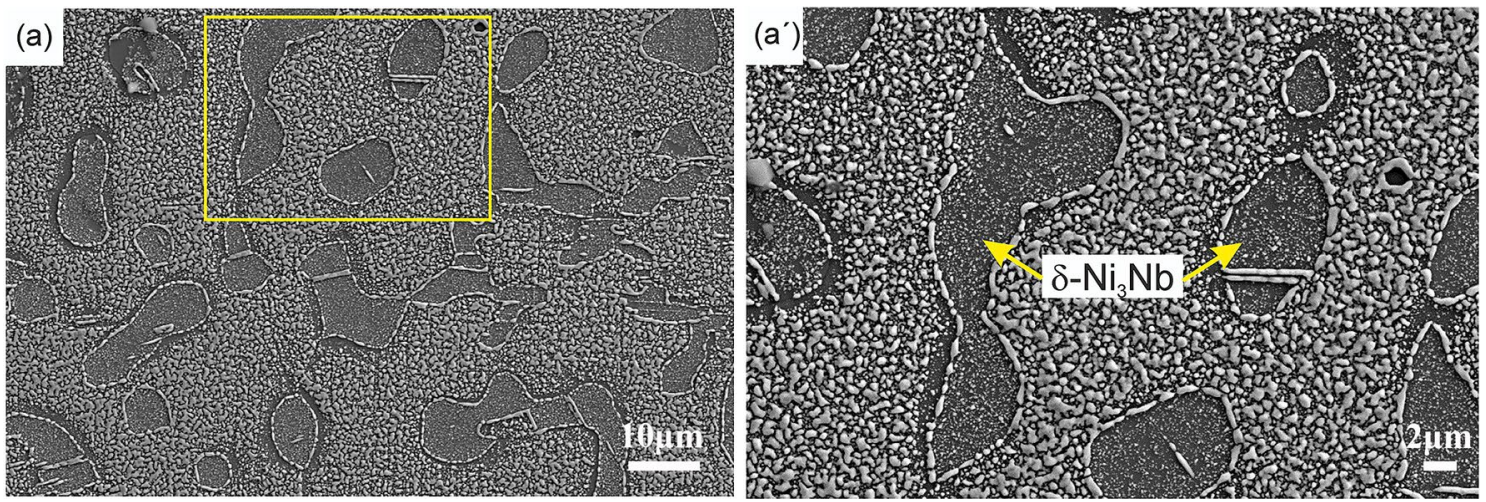

Fig. 4 a SE image of specimen immersed in Ag decoration solution with hydrogen charging; a' magnified image of yellow rectangle area in a [59]

Table 3 Similarities and differences of different hydrogen characterization methods

\begin{tabular}{|c|c|c|c|c|c|}
\hline & Method & Temperature & Sample scale & Hydrogen concentration type & Mark \\
\hline \multirow{3}{*}{$\begin{array}{l}\text { Average hydrogen } \\
\text { concentration }\end{array}$} & GM & $45^{\circ} \mathrm{C}$ & mm-scale & Diffusible hydrogen & \\
\hline & IGFHCM & $>$ Melting point & mm-scale & $\begin{array}{l}\text { Diffusible and non-diffusible } \\
\text { hydrogen }\end{array}$ & \\
\hline & TDS & $600-1000{ }^{\circ} \mathrm{C}$ & mm-scale & $\begin{array}{l}\text { Diffusible and non-diffusible } \\
\text { hydrogen }\end{array}$ & $\begin{array}{l}\text { Hydrogen trap activation } \\
\text { energy }\end{array}$ \\
\hline \multirow[t]{3}{*}{$\begin{array}{l}\text { Local hydrogen } \\
\text { concentration }\end{array}$} & SIMS & Room temperature & $\mu \mathrm{m}$-scale & $\begin{array}{l}\text { Diffusible and non-diffusible } \\
\text { hydrogen }\end{array}$ & $\begin{array}{l}\text { Hydrogen and grain boundary } \\
\text { interactions }\end{array}$ \\
\hline & HMT & Room temperature & $\mu \mathrm{m}$-scale & $\begin{array}{l}\text { Diffusible and non-diffusible } \\
\text { hydrogen }\end{array}$ & $\begin{array}{l}\text { Hydrogen and microstructure } \\
\text { interactions }\end{array}$ \\
\hline & APT & Low temperature & nm-scale & $\begin{array}{l}\text { Diffusible and non-diffusible } \\
\text { hydrogen }\end{array}$ & $\begin{array}{l}\text { Hydrogen and precipitates } \\
\text { interactions }\end{array}$ \\
\hline
\end{tabular}

Diffusible hydrogen means that hydrogen desorption occurs at $200{ }^{\circ} \mathrm{C}$ and non-diffusible hydrogen indicates that hydrogen desorption occurs at approximately $600{ }^{\circ} \mathrm{C}$ 
pipeline steels in the $\mathrm{H}_{2} \mathrm{~S}$ environment are explained by the hydrogen pressure theory. It has been recently reported [61] that the issue of "fish eye" is solved when the hydrogen content in the melted steel is controlled to be below $2 \times 10^{-6}$ (wt $\left.\%\right)$. For the HIPT theory, specific metals such as $\mathrm{Zr}, \mathrm{Nb}, \mathrm{V}$ and $\mathrm{Ta}$ combine easily with hydrogen to form brittle hydrides due to their large bond energies. In light of hydrogen concentration of the alloys, the hydrides are divided into spontaneously formed hydrides and stressinduced hydrides. At high hydrogen concentration, hydrogen directly combines with specific metals such that spontaneously formed hydrides are obtained. For stressinduced hydrides, the initially low hydrogen concentration is redistributed due to the effect of stress gradient field. Once the local hydrogen concentration reaches the solubility of metals, hydrides are precipitated. Additionally, the fracture failure mechanism of hydride-containing metals had been expounded explicitly (Fig. 5a). This mechanism is composed of four steps [62]: (1) hydrogen diffusion and accumulation at the crack tip; (2) hydride formation and growth; (3) the occurrence of a crack along a specific cleavage plane within the hydrides; and (4) the crack is arrested at the matrix/hydride interfaces. Consequently, the repetition of the above procedures leads to crack propagation. In some circumstances, hydrogen atoms from the decomposed hydrides diffuse toward the stress concentration area again and generate fresh brittle hydrides, further aggravating brittle cleavage fracture of hydrides [63].

In 1926, Pfeil et al. [65] introduced the HEDE mechanism illustrated in Fig. 5b. They suggested that hydrogen reduces the cohesive metallic interatomic interactions so that atomic separation is prone to occur under low tensile stress. As the local hydrogen concentration increases, the degree of reduction in the metallic interatomic forces increases, which is quantitatively described as [2]:

$\sigma_{\mathrm{cH}}=\sigma_{\mathrm{c} 0}-\beta C$

where $\sigma_{\mathrm{cH}}$ is the locally critical cohesive stress at the specific hydrogen concentration $C . \sigma_{\mathrm{c} 0}$ is the critical cohesive stress without hydrogen. $\beta$ is a related parameter for the loss of critical cohesive stress due to hydrogen. For the HEDE mechanism, potential hydrogen accumulation regions include: (1) the dislocation shielding region at the crack tip; (2) maximum hydrostatic stress sites; and (3) grain boundary and phase boundary at the crack tip. According to the results reported by $\mathrm{Wu}$ et al. [66] and Gao et al. [67], hydrogen concentration near the crack tip $\left(C_{\mathrm{T}}\right)$ is composed of three contributions, as expressed by:

$C_{\mathrm{T}}=C_{0}+\Delta C_{\sigma}+\Delta C_{\mathrm{PL}}$

where $C_{0}$ is the hydrogen concentration in the matrix. $\Delta C_{\sigma}$ is the hydrogen concentration caused by hydrostatic stress.
$\Delta C_{\mathrm{PL}}$ is the hydrogen concentration induced by plastic strain. For high-strength steel, hydrogen distribution at the crack tip is dominated by the hydrostatic stress, even at $2.3 \%$ plastic strain [68].

The HEDE mechanism is supported by the observation of intergranular fracture and by theoretical calculations. In intergranular fracture, similar to the role of S, P and $\mathrm{Bi}$ impurity elements, hydrogen segregates at the grain boundaries and reduces the cohesive interactions between the metal atoms, resulting in intergranular fracture [23], as shown in Fig. 6a. Using theoretical calculation, Wei et al. [69] revealed that the cohesive energies of the $[001] / 22.6^{\circ}$, $[011] / 38.9^{\circ}$ and $[111] / 60^{\circ}$ grain boundaries decreased linearly with increasing hydrogen concentration, as shown in Fig. 6b. However, the weakening of the interatomic interactions in the metal by hydrogen has not been directly demonstrated experimentally. In addition, a recent study indicated that slip bands in one or two directions are present on the grain boundary facets (Fig. 6c), beneath which severe plastic deformation with dislocation cells is detected in Ni-201 (Fig. 6d) [23]. Similar phenomena were also observed in hydrogenated iron [70] and martensitic steel [71, 72]. Thus, the role of plasticity in the HEDE mechanism should be investigated further.

In 1972, through careful observation of hydrogen-assisted fracture surfaces, Beachem et al. [73] found tear ridges on brittle fracture surfaces and proposed the HELP mechanism (Fig. 5c). In this mechanism, hydrogen facilitates dislocation proliferation and motion, causing local dislocation pileups with premature failure of the material. This mechanism has focused research attention on the interaction between the hydrogen atmosphere and dislocations, and is primarily utilized to understand plastic trace on the fracture surfaces such as dimple fracture in hydrogenated alloys. Unlike the HEDE mechanism, plasticity of the alloy plays a significant role in hydrogen-assisted fracture in the HELP mechanism.

Several phenomena provide evidence supporting the HELP mechanism (1) In situ TEM experiment. Representative researchers such as Birnbaum, Robertson and Sofronis directly observed increased dislocation mobility in the presence of hydrogen. They found that hydrogen not only induces the motion of stationary dislocations, but also increases the dislocation nucleation rate. Once hydrogen gas is removed, dislocation motion occurs in the opposite direction. These results were dependent on the purity of the material and the hydrogen gas pressure, rather than on the crystal structure (BCC and FCC) and dislocation type (edge dislocation, screw dislocation and mixed dislocation) [74, 75]. (2) Slip trace array and high dislocation density near the fracture surface. Compared to those of the hydrogenuncharged samples, both slip spacing and slip step of the hydrogen-charged samples are reduced [76]. In addition, slip features and dislocation cells are observed on and beneath 


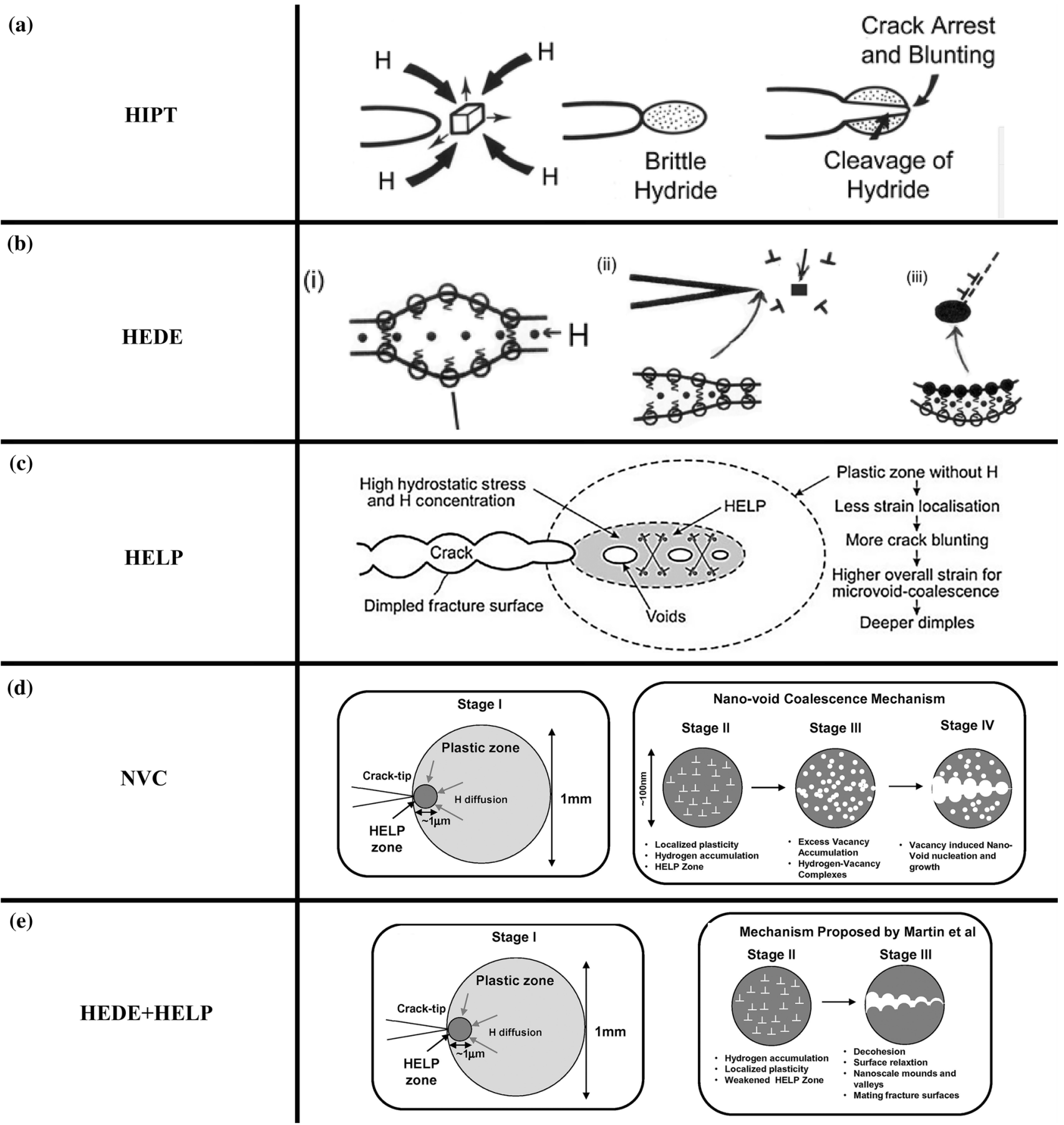

Fig. 5 Schematic diagrams of HE mechanisms. a HIPT [64]: hydrogen-induced phase transformation theory; b HEDE [64]: hydrogen-enhanced decohesion mechanism; c HELP [64]: hydrogen-enhanced localized plasticity mechanism; d NVC [5]: nanovoid coalescence mechanism; e HEDE + HELP [5]: combined effect of hydrogen-enhanced decohesion mechanism and hydrogen-enhanced localized plasticity mechanism

the brittle fracture facets. (3) Softening effect. Hydrogen can decrease the yield strength of the material and the degree of reduction is related to the crystal type, material purity, strain rate and temperature [77, 78]. For instance, hydrogeninduced softening effect is obvious at low temperatures and a low strain rate for single-crystal $\mathrm{Fe}$, whereas it is negligible for Al. (4) Elastic shielding theory. Hydrogen reduces the short-range interactions of dislocations enabling their easy migration. This shielding effect shows a dependence on the dislocation type and temperature. Further, hydrogen-induced shielding effect on the edge dislocation is much stronger 


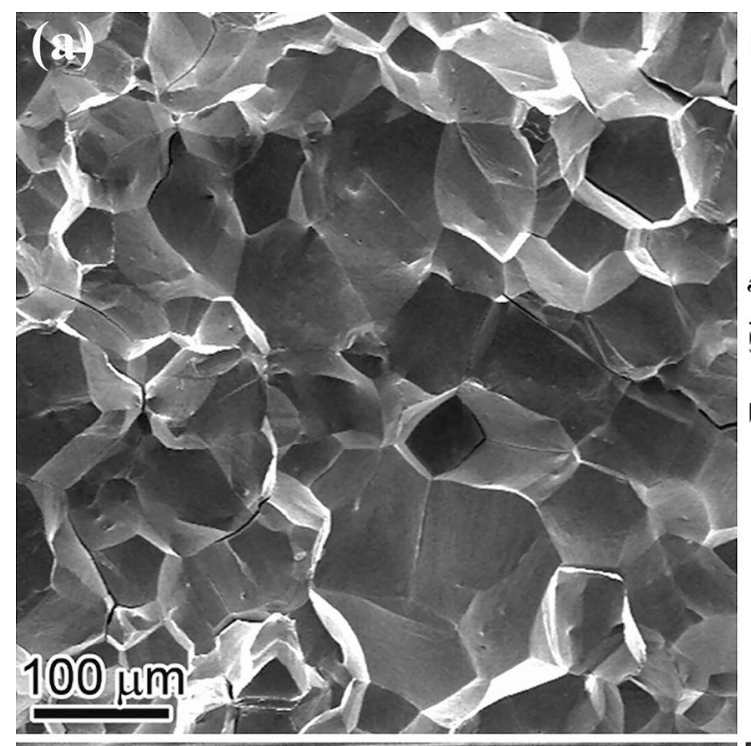

\section{(b)}
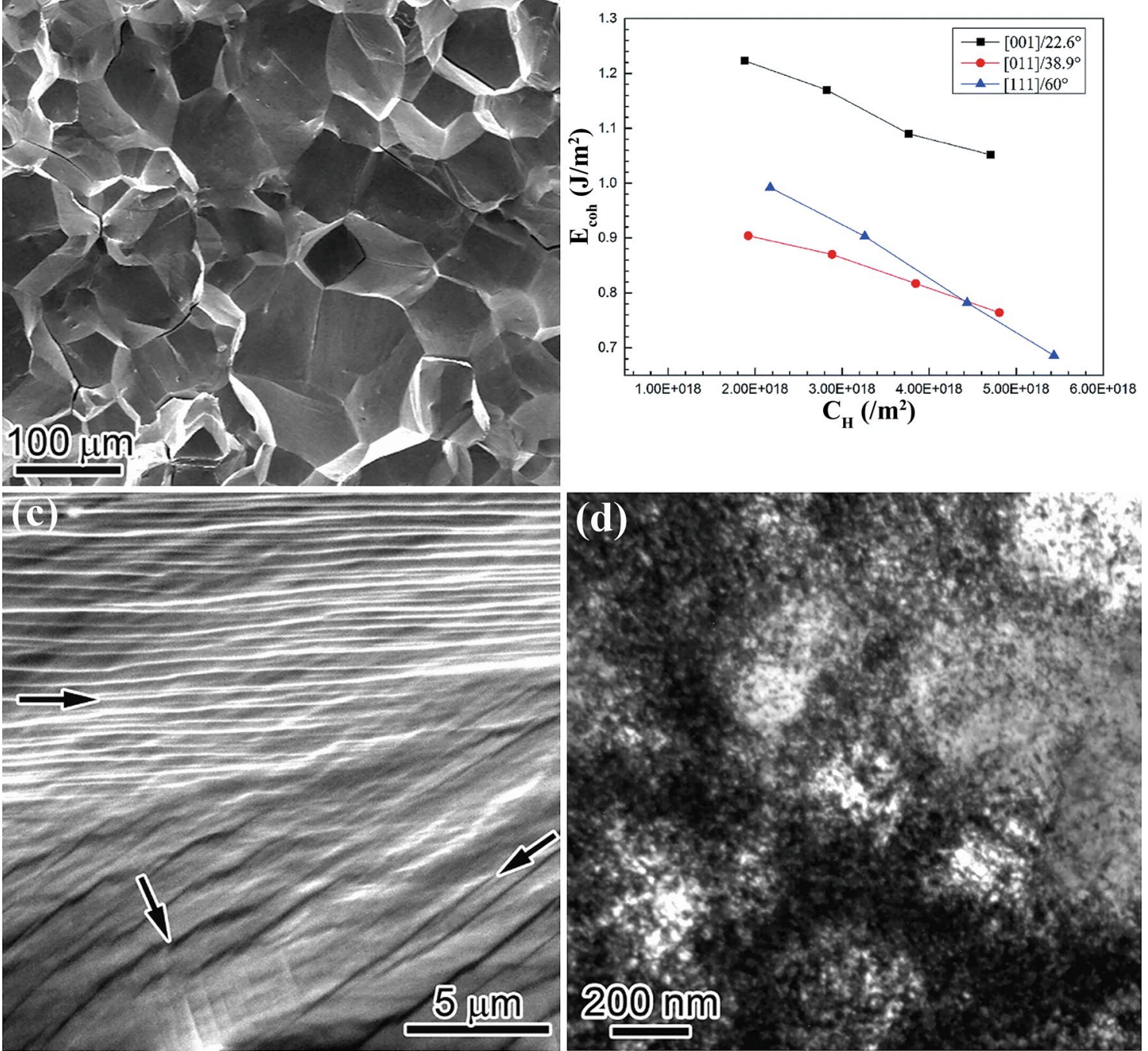

Fig. 6 a Hydrogen-induced intergranular fracture in $\mathrm{Ni}$ [23]; $\mathbf{b}$ dependence of grain boundary bonding energy on hydrogen concentration in Al [69]; c slip traces on intergranular fracture of hydrogenated Ni-201 [23]; d dislocation cells beneath hydrogen-induced intergranular fracture of $\mathrm{Ni}-201$ [23]

than that for the screw dislocation. For steels, this effect is observed in the temperature range from 180 to $200{ }^{\circ} \mathrm{C}$.

Although the HELP mechanism has been adopted to interpret HE behavior, some phenomena still cannot be explained by this mechanism. According to macroscopic tensile test results [79], hydrogen induces the Portevin-Le Chatelier effect in IN718 alloys with the suppression of dislocation motion by hydrogen. In situ microscopic tensile tests validate that dislocations in pure $\mathrm{Al}$ are dragged by hydrogen as well. Once hydrogen gas is no longer provided, the previously pinned dislocations recover and begin to move (Fig. 7a) [28]. Additionally, simulation results also indicate that hydrogen hinders dislocation mobility [24, 28]. For example, the shear stress of the dislocations in pure $\mathrm{Al}$ was of $20 \mathrm{MPa}$, increased to $40 \mathrm{MPa}$ for hydrogenated $\mathrm{Al}$ and reached $120 \mathrm{MPa}$ for the hydrogen-vacancy $\mathrm{Al}$ (Fig. 7b) [28].

In 2004, Nagumo et al. [80] suggested that the hydrogen-vacancy complex contributes to fracture failure of alloys and proposed the HESIV mechanism. This mechanism assumes that hydrogen accelerates the formation of strain-induced vacancies and stabilizes vacancy clusters, as evidenced by the positron annihilation lifetime spectrum [81] and molecular dynamics results [82]. As a result, these vacancy clusters facilitate void initiation and growth with the occurrence of premature failure. Hou et al. [83] established a predictive model for the hydrogen adatoms in nanovoids that enabled the prediction of hydrogen molecule 

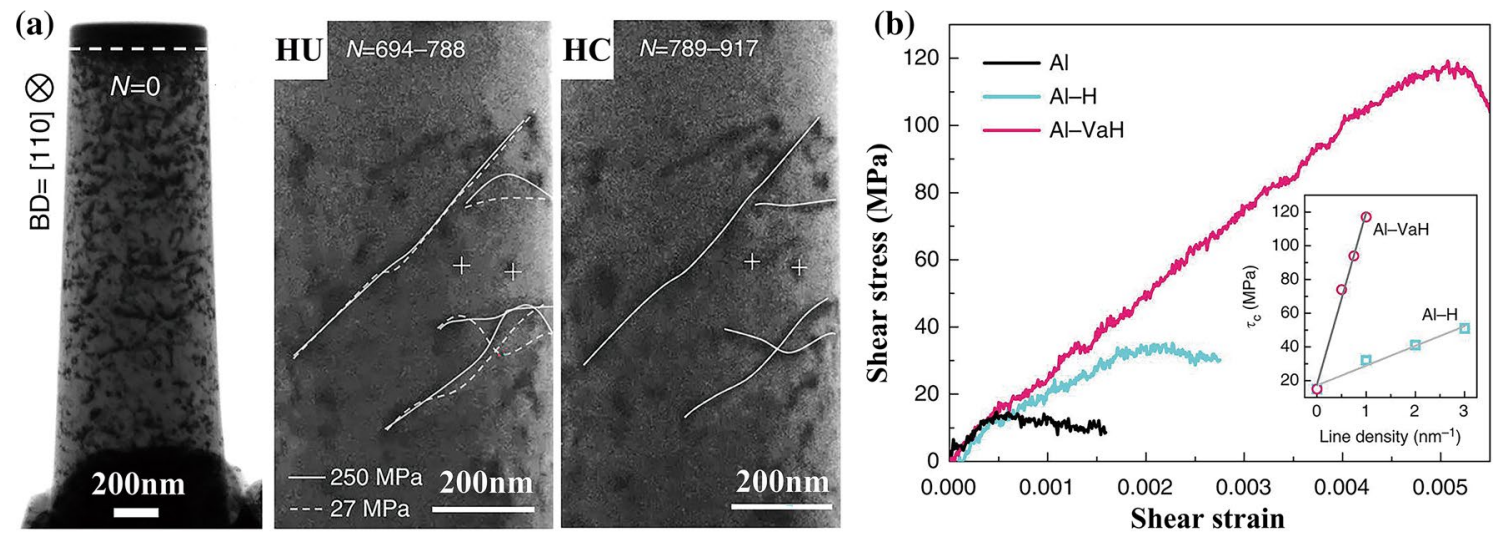

Fig. 7 a Dislocation configuration of hydrogen-uncharged and hydrogen-charged $\mathrm{Al}$ [28]; b stress-strain curve of $\mathrm{Al}, \mathrm{Al}-\mathrm{H}$ and $\mathrm{Al}-\mathrm{VaH}$ complex [28]. $H U$ hydrogen-uncharged, $H C$ hydrogen-charged, $A l-V a H$ Al-hydrogen vacancy complex

formation in nanovoids. In recent years, the activation of HEDE and HELP mechanisms has been determined by fracture surface and microstructural evolution observation. During intergranular fracture or matrix/inclusion interface decohesion, the HEDE mechanism is active, while HELP mechanism activates when hydrogen-assisted cracking initiates from the intersections between slip bands. Wang et al. [70] and Martin et al. [23, 84] observed a combination of brittle hydrogen-assisted fracture surface features with microstructural evolution beneath intergranular fracture, suggesting synergistic effect of HEDE and HELP mechanism (Fig. 5e). This joint mechanism was also established by a statistical, physical-based and micro-mechanical model of hydrogen-induced intergranular fracture in steels. Moreover, the activation of the HELP and HEDE mechanism depends on the local hydrogen concentration in low-carbon steel [85, 86]. In 2012, the nanovoid coalescence (NVC) mechanism was raised [5], as schematically shown in Fig. 5d. The essence of NVC mechanism is the simultaneous effects of the HEDE, HELP and HESIV mechanisms. It is important to note that the above-mentioned mechanisms are based on the postmortem observation of the samples, which cannot provide direct evidence for the reduction in cohesive strength by hydrogen in the HEDE mechanism and for the promotion of dislocation motion by hydrogen in the HELP mechanism.

\section{Prevention of Hydrogen Embrittlement}

Due to the effects of hydrogen concentration and stress gradient, hydrogen diffuses toward and accumulates at the stress concentration region. As the local hydrogen concentration reaches the critical value, which is still unknown, fracture failure occurs as schematically shown in Fig. 8. Usually, hydrogen sources are divided into internal hydrogen and external hydrogen. Internal hydrogen is produced in the material preparation processes, such as smelting, welding, pickling and plating, whereas hydrogen generated during service is external hydrogen and is due to corrosion, hydrogen gas and $\mathrm{H}_{2} \mathrm{~S}$ gas acid environments. Accordingly, the prevention of HE can be considered based on two approaches. The first is the use of surface treatments that involve surface coating and surface modification treatments. These methods are used to prevent external HE. The second approach is the modification of the material microstructure such as adding/eliminating the appropriate alloy elements and the optimization of the alloy microstructure.

\subsection{Surface Coating}

As a metal surface is coated with a film, the hydrogen entry into the alloy is suppressed and the alloys exhibit high HE resistance. Surface blackening treatment means the formation of an oxide layer with the thickness of $1-3 \mu \mathrm{m}$ on the metal surface, which is suitable for improving the atmospheric corrosion resistance of steels. Hydrogen permeation test results indicate that hydrogen flux and hydrogen diffusion efficiency of the blackening treatment samples are reduced in comparison with those of the non-treated samples, resulting in the enhancement of the stress corrosion delayed fracture time [88]. In addition, the surface coated by $\mathrm{Ni}, \mathrm{Cd}, \mathrm{Al}$ and $\mathrm{Al}-\mathrm{Ni}$ complex film can effectively suppress hydrogen infusion and reduce the HE susceptibility of alloys. Levchuk et al. [89] reported that the hydrogen flux of a tempered martensitic steel with $1 \mu \mathrm{m} \mathrm{Al}$ ion implantation was reduced by a factor of 1000 times than that of non-implantation steel. At a high temperature of $800^{\circ} \mathrm{C}$, the bonding strength between matrix and film was not affected. Figueroa et al. [90] revealed that AISI 4340 steel with a $\mathrm{Zn}-\mathrm{Al}$ film had higher HE resistance than that of the alloy coated by a Cd film. Zhou et al. [7] found that a Ni-graphene complex film reduced the hydrogen diffusion coefficient 


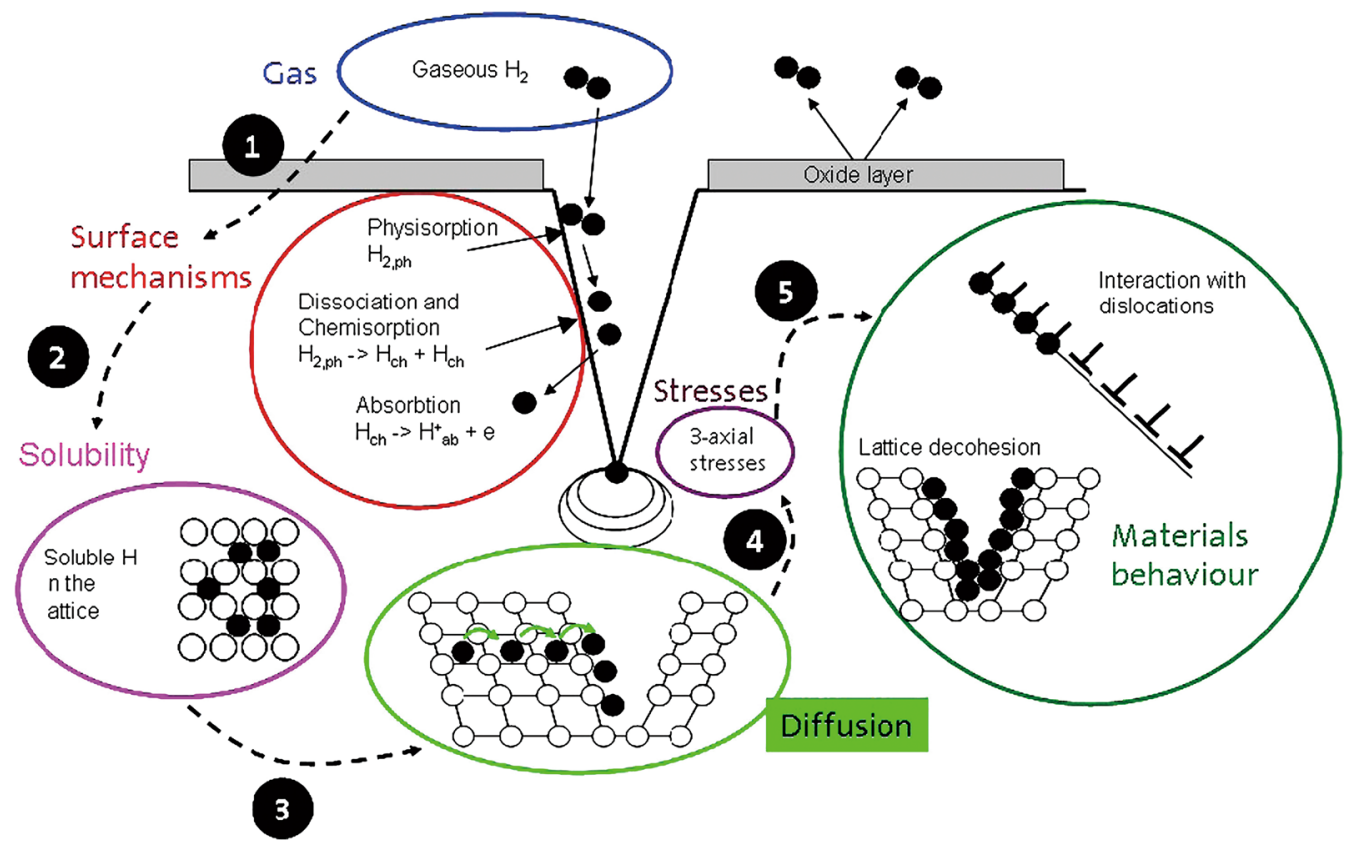

Fig. 8 Schematic diagram of hydrogen atom evolution and HE failure [87]

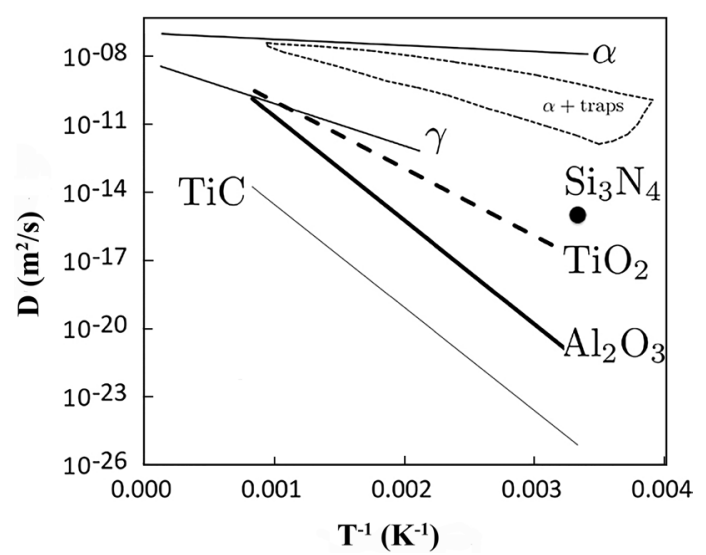

Fig. 9 Dependence of hydrogen diffusion coefficient of various films on temperatures [88] effectively compared with Ni film. Furthermore, hard films such as $\mathrm{TiC}, \mathrm{Al}_{2} \mathrm{O}_{3}$ and $\mathrm{Si}_{3} \mathrm{~N}_{4}$ can dramatically reduce hydrogen diffusion behavior, as shown in Fig. 9. It was found [91] that hydrogen diffusion coefficient of stainless steel was reduced by five orders of magnitude after a TiN film with the thickness of $1 \mu \mathrm{m}$ was coated on the steel surface. It is worth noting that hydrogen diffusion in the $\mathrm{TiC}$ and $\mathrm{Al}_{2} \mathrm{O}_{3}$ films is much slower than that in the austenite phase, suggesting that these films may act as promising barrier for enhancing the HE resistance of austenite steels.

Even though coating on the alloy surface can suppress $\mathrm{HE}$, some controversial results have been reported. Michler et al. [87] reported premature fracture of $\mathrm{Zn}, \mathrm{Ni}, \mathrm{Ti}-\mathrm{DLC}$ and NiP films at low strain (Fig. 10a) and serious defects of $\mathrm{Cu}$ film (Fig. 10b) and non-densely spherical structure of
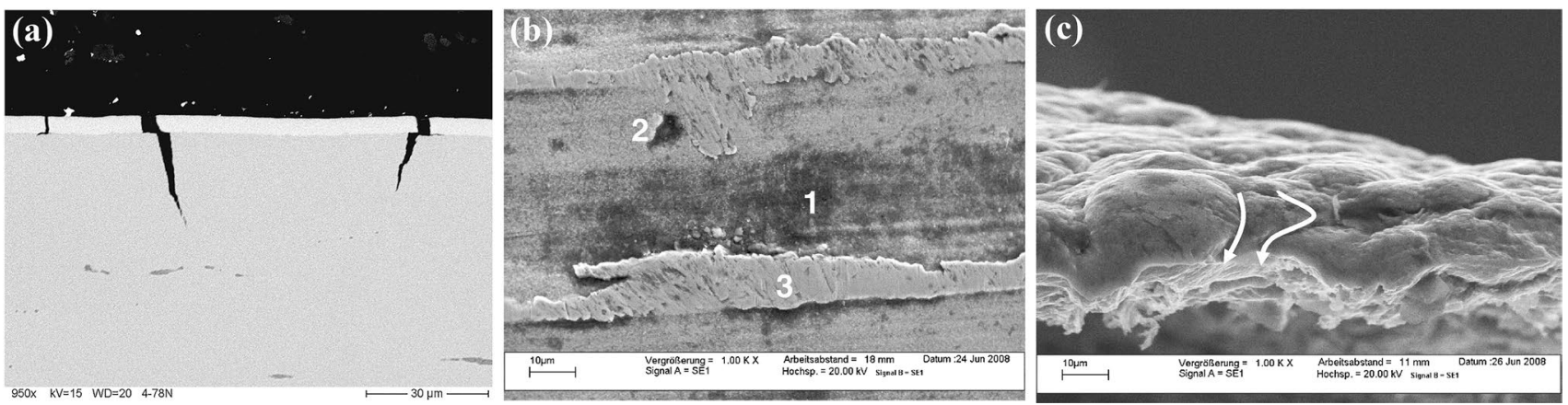

Fig. 10 a Ni film cracking at 8\% strain (1 MPa hydrogen gas, - 50) [87]; b Cu film defects, 1 micropores; 2 cracks; 3 voids [87]; c non-densely spherical structure Al film [87] 
Al film (Fig. 10c), and concluded that HE of stainless steel was not affected by the coating of these films. Nishiguchi et al. [92] found that an $\mathrm{Al}$ film can prevent hydrogen atom infusion into the steels. However, the uncoordinated deformation between the matrix and the $\mathrm{Al}$ film led to premature failure of the $\mathrm{Al} \mathrm{film}$. Thus, it is essential to optimize the film properties such as strength, plasticity, toughness and bonding strength with the matrix to enable their use as critical components for reducing HE susceptibility.

\subsection{Surface Modification}

Surface nitriding, carbonization treatment and peening treatment are promising approaches for enhancing HE resistance. On the one hand, carbon and nitrogen elements can stabilize the austenite phase, impeding the transition from austenite to martensite of the unstable 301 and 304 stainless steels [93]. In addition, interstitial carbon and nitrogen atoms reduce the lattice spacing generating compressive stress at the surface. Due to the high austenite stability and compressive stress states generated by the nitriding/carbonization treatment, the treated alloys exhibit high resistance to HE [94]. Furthermore, the HE resistance of the alloys increases distinctly when nitride the layer thickness is greater than the thickness of the hydrogen permeation layer [95]. On the other hand, surface peening treatment not only induces compressive stress, but also increases the density of the hydrogen trap sites. During hydrogen charging, hydrogen trapping sites near the surface are first occupied by hydrogen, and then, hydrogen diffuses into the interior of the alloys. Due to the peening layer barrier effect, hydrogen invasion layer in the steels is limited and the alloys exhibit low HE sensibility. For example, Takakuwa et al. [96] revealed that cavitation peening strongly enhanced the fatigue property of the hydrogen-charged 316 steel. Fracture life increased by a factor of three and fatigue crack propagation rate was reduced by $75 \%$ compared to those of hydrogen-uncharged samples. Li et al. [4] found that shot peening reduced the hydrogen permeation behavior of PSB1080 steel so that HE susceptibility of the alloy decreased. Fracture surface observation showed that shot peening treatments obstructed the occurrence of intergranular fracture. However, another study [47] indicated that reversible HE decreased, but irreversible HE increased with increasing shot peening pressure. To summarize, unlike the coating treatment, it is not necessary to consider the interface bonding behavior for the surface nitriding, carbonization and peening treatments. Moreover, the influence of novel surface treatments such as the surface nanocrystallization treatment and laser shot peening on $\mathrm{HE}$ of alloys need to be investigated.

\subsection{Materials Microstructure Modification}

Alloy elements play a prominent role in HE of steels. The reduction in HE can be obtained by reducing the amounts of the $\mathrm{C}, \mathrm{Si}, \mathrm{P}, \mathrm{S}$ elements or increasing the amounts of the $\mathrm{Ni}, \mathrm{Al}$, Mo elements. For example, it was found that HE of the $\mathrm{Mn}-\mathrm{B}$ steel increases with an increase in the $\mathrm{C}$ element content. However, the susceptibility to HE remains constant for the C content greater than 0.3\% [97]. Banerji et al. [98] reported that the threshold stress intensity factor of 4340 steels was enhanced by a factor of five after the P element content was reduced. The decrease in the $\mathrm{Cr}, \mathrm{Mn}, \mathrm{Si}$ content or increase in the Mo and Ti content can inhibit the segregation of P. According to the results of first-principles calculations [99], Al blocks hydrogen diffusion compared to the $\mathrm{Si}$ element in BCC iron. Thus, bainitic steel with high $\mathrm{Al}$ element shows low HE sensibility [100]. The addition of the $\mathrm{Cu}$ and $\mathrm{Al}$ elements to the $\mathrm{Fe}-\mathrm{Mn}-\mathrm{C}$ steel increases the stacking fault energy and reduces the stress concentration at the grain boundaries, enhancing the HE resistance of the alloy [101]. Additionally, Mo, V and Ti elements often combine with C to form carbides, which serve as irreversible hydrogen traps and thus enhance the HE resistance of the alloy.

HE of steels depends on their microstructures. Specifically, the martensitic structure shows the highest HE susceptibility, followed by bainite, pearlite and austenite in turn. Ninninga et al. [102] reported that fastener steels with pearlitic microstructure exhibited lower HE susceptibility compared to bainitic steel. It was found [103] that pearlitic steel possessed higher HE resistance than martensitic steel, while both of these types of steels have the same strength level. For austenite, the HE susceptibility of the alloys is correlated with its content, shape and stability. Owing to low hydrogen diffusion and high hydrogen solubility in austenite, an increase in the austenite content leads to the reduction in HE of steels [104]. Compared to film-shaped austenite, hydrogen-assisted cracking preferentially initiates from block residual austenite sites, and therefore, the steels with film-shaped austenite show lower HE [105]. Based on the results obtained by Wang et al. [106], hydrogen-assisted cracking originates from the interfaces between the freshly formed martensite from austenite and original martensite, indicating that the increased austenite stabilization, such as the addition of $\mathrm{C}$ element, can enhance HE resistance. In addition, carbides always increase HE resistance of steels. However, Lee et al. [107] reported that HE sensibility of martensitic steels firstly decreased and then increased with increasing carbide content. Kang et al. [57] indicated that sphere-shaped carbides inhibited crack initiation and propagation, while cracking was prone to occur for steels containing needle-shaped carbides in the presence of hydrogen. The role of nanoscale precipitates on HE of steels has been controversial. Due to the interactions between the dislocations 
and precipitates, the strength of the alloys increases, which corresponds to low resistance to HE. By contrast, precipitates in the steels serve as reversible hydrogen traps and reduce the local hydrogen concentration accumulation, leading to low HE susceptibility. For example, Shi et al. [108] revealed that the pipeline steel with enriched $\mathrm{Cu}$ precipitates exhibited excellent resistance to hydrogen-induced cracking. Kimura et al. [109] reported that the critical hydrogen concentration of the steel with $10 \mathrm{~nm} \mathrm{Cr}_{2} \mathrm{O}_{3}$ precipitates was enhanced significantly in comparison with traditionally manufactured martensitic steel. However, Li et al. [2] have recently reported the higher HE sensibility of PH13-8Mo steel primarily strengthened by coherent $\mathrm{NiAl}$ precipitates compared to that of $20 \mathrm{SiMn} 2 \mathrm{CrNiMo}$ steel. Finally, any types of inclusions such as $\mathrm{MnS}, \mathrm{O}-\mathrm{Al}-\mathrm{Si}-\mathrm{Ca}$ and $\mathrm{TiN}$ inclusions are not beneficial for HE of steels because they often act as hydrogen-assisted crack initiation sites. Thus, this suggests that a reduction in the amount of inclusion can be used to enhance HE resistance of the alloys.

\section{Conclusions and Outlook}

With the aid of advanced equipment, the understanding of HE mechanism has shifted from microscale (HEDE) to nanoscale (HELP, HESIV). However, some issues persist: (1) for the HEDE mechanism, experimental proof for the quantitative relationship between the local hydrogen concentration and atomic bonding interactions has been lacking, although the data from theoretical calculations have been available; (2) the role of plastic deformation on HE mechanism has been unclear. For example, do plastic features such as tear ridges on grain boundaries contribute to brittle fracture or are the plastic features themselves the results of brittle fracture separation? (3) according to the postmortem microstructural evolution characterization and fracture surface observation, NVC mechanism and synergistic effect of HEDE and HELP mechanism have been proposed. However, no direct evidence supports these mechanisms; (4) all the existing HE mechanisms are valid only for certain materials in certain applications and a uniform HE mechanism for all materials is yet to be developed.

As coatings are utilized to prevent HE failure, coating defects, plasticity and bonding strength between the matrix and coating should be considered. For peening treatments, surface residual compressive stress is recommended for HE prevention, because hydrogen entry is suppressed by the compression of the crystal lattice. Furthermore, for the strategy of preventing HE on austenite microstructure modification, austenite morphology and stabilization are important. In this case, film-shaped austenite should be preferentially selected. Meanwhile, an appropriate addition of austenite-stabilized elements such as $\mathrm{C}, \mathrm{N}, \mathrm{Ni}$ and $\mathrm{Mn}$ is recommended. For precipitation-strengthened steels, dislocations interact with the stress-strain field generated by the misfit between the matrix and the precipitates. In this case, dislocation motion is suppressed with increasing strength level of steels, which corresponds to high HE. Meanwhile, high-density precipitates act as hydrogen traps with the reduction in the local hydrogen concentration. Based on this, the presence of precipitates in steels can impede HE. Thus, it appears that nanosized precipitates have a dual effect on the HE of precipitation-strengthened steels. However, it is still necessary to determine the density of the nanosized precipitates, at which the steel exhibits the lowest HE susceptibility.

Acknowledgements This work was financially supported by the National Natural Science Foundation of China (No. 51505477), the Guangdong Provincial Key S\&T Special Project (Nos. 2017B020235001 and 2019B010943001) and the Guangdong Education Department Fund (No. 2016KQNCX005). X. Li appreciates basic start-up fund of Sun-Yat Sen University (45000-18841218).

\section{References}

[1] X. Li, Z. Jin, Z. Peng, L. Pei, X. Song, J Fail Anal Prev. 15, 295 (2015)

[2] X. Li, J. Zhang, Q. Fu, X. Song, S. Shen, Q. Li, Mater. Sci. Eng. A 724, 518 (2018)

[3] X. Li, J. Zhang, S. Shen, Y. Wang, X. Song, Mater. Sci. Eng. A 682, 359 (2017)

[4] X.F. Li, J. Zhang, M.M. Ma, X.L. Song, Int. J. Min. Met. Mater. 23, 667 (2016)

[5] T. Neeraj, R. Srinivasan, J. Li, Acta Mater. 60, 5160 (2012)

[6] Z. Xu, L. Wei, T.Y. Hsu, Z. Shu, W. Li, X. Jin, Scr. Mater. 97, 21 (2015)

[7] P. Zhou, L. Wei, Z. Xu, L. Yu, C. Jian, J. Electrochem. Soc. 163, 160 (2016)

[8] T. Zhao, Z. Liu, X. Xu, Y. Li, C. Du, X. Liu, Corros. Sci. 157, 146 (2019)

[9] J.A. Ronevich, B.P. Somerday, C.W. San Marchi, Int. J. Fatigue 82, 497 (2016)

[10] A. Alvaro, D. Wan, V. Olden, A. Barnoush, Eng. Fract. Mech. 219, 106641 (2019)

[11] Y. Ogawa, H. Matsunaga, J. Yamabe, M. Yoshikawa, S. Matsuoka, Int. J. Hydrog. Energy 43, 20133 (2018)

[12] R. Wang, Corros. Sci. 51, 2803 (2009)

[13] E. Chatzidouros, A. Traidia, R. Devarapalli, D. Pantelis, T. Steriotis, M. Jouiad, Int. J. Hydrog. Energy 43, 5747 (2018)

[14] Y. Song, M. Chai, B. Yang, Z. Han, S. Ai, Y. Liu, G. Cheng, Y. Li, Materials 11, 1068 (2018)

[15] M.S. Bhuiyan, H. Toda, K. Shimizu, H. Su, K. Uesugi, A. Takeuchi, Y. Watanabe, Metall. Mater. Trans. A 49, 5368 (2018)

[16] S. Pallaspuro, H. Yu, A. Kisko, D. Porter, Z. Zhang, Mater. Sci. Eng. A 688, 190 (2017)

[17] J. Yamabe, M. Yoshikawa, H. Matsunaga, S. Matsuoka, Procedia Struct. Integr. 2, 525 (2016)

[18] S. Serebrinsky, E. Carter, M. Ortiz, J. Mech. Phys. Solids 52, 2403 (2004)

[19] Y. Wang, J. Gong, W. Jiang, Y. Jiang, J. Tang, Acta Metall. Sin. 47, 594 (2011). (in Chinese)

[20] V. Olden, C. Thaulow, R. Johnsen, Mater. Des. 29, 1934 (2008)

[21] X. Xing, W. Chen, H. Zhang, Mater. Lett. 152, 86 (2015) 
[22] M. Yu, X. Xing, H. Zhang, J. Zhao, R. Eadie, W. Chen, J. Been, G. Van Boven, R. Kania, Acta Mater. 96, 159 (2015)

[23] M.L. Martin, B.P. Somerday, R.O. Ritchie, P. Sofronis, I.M. Robertson, Acta Mater. 60, 2379 (2012)

[24] J. Song, W. Curtin, Nat. Mater. 12, 145 (2013)

[25] J. Song, W.A. Curtin, Acta Mater. 68, 61 (2014)

[26] H. Yu, A. Cocks, E. Tarleton, J. Mech. Phys. Solids 123, 41 (2019)

[27] W. Xie, X. Liu, W. Chen, H. Zhang, Comput. Mater. Sci. 50, 3379 (2011)

[28] D. Xie, S. Li, M. Li, Z. Wang, P. Gumbsch, J. Sun, E. Ma, J. Li, Z. Shan, Nat. Commun. 7, 13341 (2016)

[29] Q. Liu, A. Atrens, Corros. Rev. 31, 85 (2013)

[30] J.-G. Sezgin, C. Bosch, A. Montouchet, G. Perrin, K. Wolski, Int. J. Hydrog. Energy 42, 15403 (2017)

[31] T.P. Perng, J.K. Wu, Mater. Lett. 57, 3437 (2003)

[32] A. Lasia, J. Electrochem. Soc. 142, 3393 (1995)

[33] L. Qian, A.D. Atrens, Z. Shi, K. Verbeken, A. Atrens, Corros. Sci. 87, 239 (2014)

[34] J. Venezuela, C. Tapia-Bastidas, Q. Zhou, T. Depover, K. Verbeken, E. Gray, Q. Liu, L. Qian, M. Zhang, A. Atrens, Corros. Sci. 132, 90 (2017)

[35] R.N. Iyer, H.W. Pickering, M. Zamanzadeh, J. Electrochem. Soc. 136, 2463 (1989)

[36] M. Devanathan, Z. Stachurski, J. Electrochem. Soc. 111, 619 (1964)

[37] B. Chao, S.H. Chae, X. Zhang, K.H. Lu, J. Im, P.S. Ho, Acta Mater. 55, 2805 (2007)

[38] K. Kiuchi, R.B. Mclellan, Acta Metall. 31, 961 (1983)

[39] A. Pundt, R. Kirchheim, Annu. Rev. Mater. Res. 36, 555 (2006)

[40] G.M. Pressouyre, Metall. Trans. A 10, 1571 (1979)

[41] M. Nagumo, M. Nakamura, K. Takai, Metall. Mater. Trans. A 32, 339 (2001)

[42] S.K. Yen, I.B. Huang, Mater. Chem. Phys. 80, 662 (2003)

[43] C.F. Dong, Z.Y. Liu, X.G. Li, Y.F. Cheng, Int. J. Hydrog. Energy 34, 9879 (2009)

[44] H. Addach, P. Bercot, M. Rezrazi, M. Wery, Mater. Lett. 59, 1347 (2005)

[45] Y. Wang, X. Wang, J. Gong, L. Shen, W. Dong, Int. J. Hydrog. Energy 39, 13909 (2014)

[46] V. Ramunni, T.D.P. Coelho, P.V. de Miranda, Mater. Sci. Eng. A 435, 504 (2006)

[47] X. Li, J. Zhang, Y. Wang, M. Ma, S. Shen, X. Song, Mater. Des. 110, 602 (2016)

[48] D. Figueroa, M. Robinson, Corros. Sci. 52, 1593 (2010)

[49] X. Li, J. Zhang, Q. Fu, E. Akiyama, X. Song, S. Shen, Mater. Sci. Eng. A 742, 353 (2019)

[50] J. Yamabe, T. Awane, S. Matsuoka, Int. J. Hydrog. Energy 40, $10329(2015)$

[51] A. Oudriss, S. Le Guernic, Z. Wang, B. Osman Hoch, J. Bouhattate, E. Conforto, Z. Zhu, D.S. Li, X. Feaugas, Mater. Lett. 165, 217 (2016)

[52] X. Cheng, Z. Zhang, W. Liu, X. Wang, Prog. Nat. Sci. Mater. Int. 23, 446 (2013)

[53] X. Zhu, L.I. Wei, H. Zhao, L.I. Wang, X. Jin, Int. J. Hydrog. Energy 39, 13031 (2014)

[54] X. Zhu, W. Li, T. Hsu, S. Zhou, L. Wang, X. Jin, Scr. Mater. 97, $21(2015)$

[55] X. Zhu, W. Li, H. Zhao, L. Wang, X. Jin, Int. J. Hydrog. Energy 39, 13031 (2014)

[56] W.Y. Choo, J.Y. Lee, Metall. Trans. A 13, 135 (1982)

[57] H.J. Kang, J.S. Yoo, J.I. Tae Park, S.T. Ahn, Kang. Mater. Sci. Eng. A 543, 6 (2012)

[58] J. Ovejero-García, J. Mater. Sci. 20, 2623 (1985)
[59] Z. Tarzimoghadam, M. Rohwerder, S.V. Merzlikin, A. Bashir, L. Yedra, S. Eswara, D. Ponge, D. Raabe, Acta Mater. 109, 69 (2016)

[60] C. Zapffe, C. Sims, Trans. AIME 145, 225 (1941)

[61] X.C. Ren, W.Y. Zhu, J.X. Li, L.J. Qiao, B. Jiang, G. Chen, Y.H. Cui, Acta Metall. Sin. 42, 153 (2006). (in Chinese)

[62] C.D. Cann, E.E. Sexton, Acta Metall. 28, 1215 (1980)

[63] R. Dutton, K. Nuttall, M.P. Puls, L.A. Simpson, Metall. Trans. A 8, 1553 (1977)

[64] S. P. Lynch. Progress Towards Understanding Mechanisms Of Hydrogen Embrittlement And Stress CorrosionCracking[J]. Nace International Corrosion Conference (2007)

[65] L.B. Pfeil, The effect of occluded hydrogen on the tensile strength of iron, in Proceedings of the Royal Society of London. Series A, Containing Papers of a Mathematical and Physical Character. vol. 112 (1926), pp. 182-195

[66] S.D. Wu, L. Chen, M.Z. Liu, Acta Metall. Sin. 26, 10 (1990). (in Chinese)

[67] H. Gao, W. Cao, C. Fang, E.R.D.L. Rios, Fatigue Fract. Eng. Mater. 17, 1213 (2010)

[68] J. Lufrano, P. Sofronis, Acta Mater. 46, 1519 (1998)

[69] X. Wei, C. Dong, Z. Chen, K. Xiao, X. Li, RSC Adv. 6, 27282 (2016)

[70] W. Shuai, M.L. Martin, P. Sofronis, S. Ohnuki, N. Hashimoto, I.M. Robertson, Acta Mater. 69, 275 (2014)

[71] A. Nagao, C.D. Smith, M. Dadfarnia, P. Sofronis, I.M. Robertson, Acta Mater. 60, 5182 (2012)

[72] A. Nagao, M.L. Martin, M. Dadfarnia, P. Sofronis, I.M. Robertson, Acta Mater. 74, 244 (2014)

[73] C.D. Beachem, Metall. Trans. 3, 441 (1972)

[74] I.M. Robertson, Eng. Fract. Mech. 68, 671 (2001)

[75] I.M. Robertson, P. Sofronis, A. Nagao, M.L. Martin, S. Wang, D.W. Gross, K.E. Nygren, Metall. Mater. Trans. A 46, 1085 (2015)

[76] D.P. Abraham, C.J. Altstetter, Metall. Mater. Trans. A 26, 2859 (1995)

[77] H. Matsui, H. Kimura, A. Kimura, Strength Met. Alloys 2, 977 (1979)

[78] J.P. Hirth, Metall. Trans. A 11, 861 (1980)

[79] X. Li, J. Zhang, E. Akiyama, Q. Fu, Q. Li, J. Mater. Sci. Technol. 35, 499 (2019)

[80] M. Nagumo, Mater. Sci. Technol. 20, 940 (2004)

[81] K. Sakaki, T. Kawase, M. Hirato, M. Mizuno, H. Araki, Y. Shirai, M. Nagumo, Scr. Mater. 55, 1031 (2006)

[82] M. Wen, L. Zhang, B. An, S. Fukuyama, K. Yokogawa, Phys. Rev. B 80, 94113 (2009)

[83] J. Hou, X.S. Kong, X. Wu, J. Song, C. Liu, Nat. Mater. 18, 833 (2019)

[84] M.L. Martin, I.M. Robertson, P. Sofronis, Scr. Mater. 59, 3680 (2011)

[85] M. Djukic, V.S. Zeravcic, G. Bakic, A. Sedmak, B. Rajicic, Procedia Mater. Sci. 3, 1167 (2014)

[86] M. Djukic, V.S. Zeravcic, G. Bakic, A. Sedmak, B. Rajicic, Eng. Fail. Anal. 58, 485 (2015)

[87] T. Michler, Surf. Coat. Technol. 203, 1819 (2009)

[88] H.K.D.H. Bhadeshia, ISIJ Int. 56, 24 (2016)

[89] D. Levchuk, F. Koch, H. Maier, H. Bolt, J. Nucl. Mater. 328, 103 (2004)

[90] D. Figueroa, M.J. Robinson, Corros. Sci. 50, 1066 (2008)

[91] K. Saito, S. Inayoshi, Y. Ikeda, Y. Yang, S. Tsukahara, J. Vac. Sci. Technol. A 13, 556 (1995)

[92] K. Hiroharu, N. Hiroshi, F. Takumi, O. Tamiko, Y. Yoshihito, I. Takeshi, S. Masanori, S. Yoshiaki, Jpn. J. Appl. Phys. 57, 1 (2018)

[93] T. Michler, Surf. Coat. Technol. 202, 1688 (2008) 
[94] X. Liu, W. Xie, W. Chen, H. Zhang, J. Mater. Res. 26, 2735 (2011)

[95] T. Tsuchiyama, K. Tsuboi, S. Iwanaga, T. Masumura, A. Macadre, N. Nakada, S. Takaki, Scr. Mater. 90-91, 14 (2014)

[96] O. Takakuwa, H. Soyama, Int. J. Hydrog. Energy 37, 5268 (2012)

[97] Y. Zhang, C. Zhou, W. Hui, H. Dong, J. Iron Steel Res. 26, 49 (2014)

[98] S.K. Banerji, C.J. Mcmahon, H.C. Feng, Metall. Trans. A 9, 237 (1978)

[99] B. Han, Dissertation, Yanshan University (2010)

[100] C. Zheng, L.V. Bo, F. Zhang, Z. Yan, R. Dan, L. Qian, Mater. Sci. Eng. A 547, 99 (2012)

[101] T. Dieudonné, L. Marchetti, M. Wery, J. Chêne, C. Allely, P. Cugy, C.P. Scott, Corros. Sci. 82, 218 (2014)

[102] T. Nanninga, Corros. Sci. 52, 1237 (2010)
[103] S.K. Ji, H.L. You, D.L. Lee, K.T. Park, S.L. Chong, Mater. Sci. Eng. A 505, 105 (2009)

[104] L.W. Tsay, M.Y. Chi, H.R. Chen, C. Chen, Mater. Sci. Eng. A 416, 155 (2006)

[105] X. Zhu, K. Zhang, W. Li, X. Jin, Mater. Sci. Eng. A 658, 400 (2016)

[106] M. Wang, C.C. Tasan, M. Koyama, D. Ponge, D. Raabe, Metall. Mater. Trans. A 46, 3797 (2001)

[107] J. Lee, T. Lee, Y.J. Kwon, D.J. Mun, J.Y. Yoo, S.L. Chong, Met. Mater. Int. 22, 364 (2016)

[108] X. Shi, W. Yan, W. Wang, Y. Shan, K. Yang, Mater. Des. 92, 300 (2016)

[109] Y. Kimura, Y. Sakai, T. Hara, A. Belyakov, K. Tsuzaki, Scr. Mater. 49, 1111 (2003) 